\title{
A naturalistic study on the relationship among resilient factors, psychiatric symptoms, and psychosocial functioning in a sample of residential patients with psychosis
}

This article was published in the following Dove Press journal:

Psychology Research and Behavior Management

\section{Nicola Poloni \\ Daniele Zizolfi \\ Marta Ielmini \\ Roberto Pagani \\ Ivano Caselli \\ Marcello Diurni \\ Anna Milano \\ Camilla Callegari}

Department of Medicine and Surgery, Division of Psychiatry, University of Insubria, Varese, Italy
Correspondence: Camilla Callegari Department of Medicine and Surgery, Division of Psychiatry, University of Insubria, Viale Luigi Borri 57, 21100 Varese, Italy Email camilla.callegari@uninsubria.it
Objective: Resilience is a multidimensional process of adaptation aimed to overcome stressful or traumatic life experiences; only in the last few years it has been considered as a personal resource in psychosis and schizophrenia. This study aimed to assess the relationship between intrapersonal and interpersonal resilience factors and schizophrenia, particularly whether and how resilience can improve the course of psychotic illness.

Patients and methods: In this observational study, all patients recruited had to fulfill the following inclusion criteria: diagnosis of schizophrenia spectrum disorder (Diagnostic and Statistical Manual of Mental Disorders-5); aged between 18 and 65 years; provided written informed consent; to be clinically stable (Clinical Global Impression Scale $<3$ ); history of illness $\geq 5$ years; to be compliant with antipsychotic therapy over the last year; and regular submission to periodic monthly psychiatric visits. Patients were evaluated through the following scales: Resilience Scale for Adults (RSA) for resilience; Brief Psychiatric Rating Scale-Anchored version (BPRS-A), Scale for the Assessment of Negative Symptoms (SANS), and Scale for the Assessment of Positive Symptoms (SAPS) for psychotic symptomatology; and Life Skills Profile (LSP) for psychosocial functioning. Statistical analysis was performed by SPSS. Partial correlations were evaluated to assess the relationship between RSA total scores and subscores and BPRS-A, SANS, SAPS, and LSP total scores, removing the common variance among variables. Then, a series of hierarchical multiple linear regression models were used to examine the association between resilience, psychopathology, and psychosocial functioning.

Results: A statistically significant negative correlation among intrapersonal resilience factors and BPRS-A total score emerged, predicting psychiatric symptoms severity and explaining approximately $31 \%$ of the BPRS-A variance; otherwise, only the interpersonal resilience factors associated with social support were statistically and positively correlated with LSP total score, predicting psychosocial functioning and explaining the $11 \%$ of LSP variance.

Conclusion: The specific contribution that resilience factors may have in predicting the severity of symptoms and the extent of psychosocial functioning emphasizes the importance of personalizing treatment for patients affected by schizophrenia, promoting personal resources, and translating them into better outcomes.

Keywords: resilience, personal resources, psychosis, schizophrenia, residential patients, psychosocial functioning

\section{Introduction}

Resilience has been extensively studied, but only in the last few years it has been considered as a personal resource and a therapeutic factor in severe psychiatric syndromes, such as schizophrenia. ${ }^{1-3}$ 
However, resilience, which in psychology is defined as a dynamic process of adaptation aimed to face and overcome stressful or traumatic life experiences, emerging transformed and even strengthened, ${ }^{4-8}$ has often been considered as a unitary construct, not enhancing its various dimensions. Moreover, resilience does not mean adapting passively to the context, but it rather reflects the ability to redesign the relationship with one's own environment, enhancing themselves and their context. ${ }^{9}$

Several authors have identified three different factors of resilience: ${ }^{10-18}$ psychological and dispositional abilities, family cohesion, and external support. Personal resources include personality traits that distinguish the resilient subject: emotional stability, autonomy, adaptability, and strong ability to plan and organize life. ${ }^{19,20}$ Family and individual microcosms have a particular role for the development of resilience: some authors ${ }^{13,15,21}$ emphasize the importance of external protection factors such as having positive parental figures, emotional support with friends and family solidarity, work and job prospects, marriage, and relationship with children. Also, interpersonal relationships, external support, and real and perceived social role, such as good inclusion in the sociocultural context, facilitate the development of resilient attitudes, making it easier to get external support from others and satisfy the human need to participate in a wider context. ${ }^{13,18}$ In conclusion, resilience must be considered as a multidimensional construct. It does not only refer to psychological skills but also to the individual's ability to use family, social, and external support systems to cope better with stress. ${ }^{22,23}$

Resilience, such as recovery style and coping style, is therefore considered a key factor in dealing with major psychiatric disorders; several authors showed that it can contribute to influence the course of some important diseases. ${ }^{1-3,7,24-27}$ Starting from this evidence, it is interesting to study the correlation between resilience and schizophrenia. In fact, despite the latest advances in psychopharmacology and the use of integrated treatments (pharmacological, psychological, and psychoeducational approaches), schizophrenia is still among the major causes of disability worldwide. ${ }^{28}$ The most common psychotic symptoms, such as positive and negative symptoms, disorganization, and neurocognitive impairment, are responsible for a serious mental illness, affecting severely the patients' quality of life of everyday living. ${ }^{29,30}$ They involve a range of emotional and behavioral dysfunctions and have a negative impact on patients' relatives, caregivers, and psychiatric professionals; ${ }^{31-33}$ finally, they seriously compromise real-life psychosocial functioning, including independent living, productive activities, and social relationships. ${ }^{34,35}$ The lessening of symptoms attributable to psychopharmacological therapy contributes to improve the quality of life and the psychosocial functioning, but is not enough to obtain functional recovery; ${ }^{36-38}$ psychological, psychosocial, and rehabilitative interventions are essential to guarantee the development of patient recovery and promote its social reintegration. ${ }^{39-41}$ The identification and development of personal resources could integrate and empower recovery strategies and ensure more positive outcomes, in both psychosocial functioning and symptomatology. ${ }^{1-3,24,25,39-42}$

Some recent research showed a correlation between resilience and real-life functioning in patients with schizophrenia, and no associations between resilience and psychotic symptoms; ${ }^{1-3,42}$ however, these studies have taken into account resilience as a unitary construct, not enhancing its different factors; furthermore, they valued only positive and negative symptoms of psychosis, leaving general psychopathology.

In this study, we assess the relationship between resilience factors and schizophrenia, particularly whether and how resilience can improve the course of psychotic illness. The primary aim is to identify, in a sample of patients affected by schizophrenia, any correlations between resilience factors and psychotic symptoms, general psychopathology, and psychosocial functioning, highlighting any statistically significant difference between two different psychotic disorders belonging to schizophrenia spectrum disorders: schizophrenia and schizoaffective disorder. Second, the study aimed to verify if resilience factors can predict symptoms severity and the level of psychosocial functioning. Finally, the possible interplay between resilience factors and psychopathology on psychosocial functioning was evaluated.

\section{Patients and methods Participants and procedures}

In this observational, retrospective, naturalistic study, participants were recruited from residential, accredited psychiatric facilities in Lombardy, Italy (Deliberate no. VIII/4221, February 28, 2007). The Lombardy region has mandated Agenzie di Tutela della Salute (ATS) to control all health services which can be delivered from public or private/accredited hospitals. Some public hospitals are university hospitals with many university units, as our psychiatric unit, headed by university professors; in this case, researchers work alongside clinicians.

Inclusion criteria were diagnosis of a schizophrenia spectrum disorder (schizophrenia or schizoaffective disorder) according to Diagnostic and Statistical Manual of Mental Disorders-5; aged between 18 and 65 years; to sign a written 
informed consent statement; to be clinically stable (Clinical Global Impression Scale $<3$ ); history of illness $\geq 5$ years; to be compliant with antipsychotic therapy over the last year; and regular submission to periodic monthly psychiatric visits.

Exclusion criteria were inability to provide informed consent; history of significant organic and physical handicaps or mental retardation; phase of symptomatic acuity at the time of inclusion; and current pregnancy or lactation.

All patients provided written informed consent to participate after receiving a comprehensive explanation of the study procedures and goals for processing the personal data. Data were made anonymous and unidentifiable. The Provincial Health Ethical Review Board was consulted prior to the beginning of the study, and it confirmed that, as it was a retrospective naturalistic study, it did not need authorization from the Board. The assessment tools and scales were administered by clinicians at the patients' facilities as part of the clinical routine. Researchers were able to collect the data of patients of residential psychiatric facilities of the same ATS.

\section{Assessment tools}

\section{Resilience Scale for Adults (RSA)}

RSA is a self-administered scale including 33 items; it is based on the use of a seven-point semantic differential, with the purpose to limit acquiescence. ${ }^{43-45}$ Items are divided into six subscales that explore resilient factors that can help people face and overcome stressful or traumatic life experiences. Subscales cover six different intrapersonal and interpersonal resilient factors: "perception of self" (six items), "perception of the future" (four items), "structured style" (four items), "social competence" (six items), "family cohesion" (six items), and "social resources" (seven items). "Perception of self," "perception of the future," "structured style," and "social competence" reflect personal abilities of the subjects assessing the level of self-esteem, self-efficacy, and self-liking; hope, determination, and a realistic orientation to life; the ability to uphold daily routine, to plan and organize; and finally, the individual's competence to provide support. "Family cohesion" measures instead the amount of family conflict, cooperation, support, loyalty, and stability; it refers to the domains of family support. The external support system was finally expressed by the subscale "social support" that measured access to external support from friends and relatives and intimacy. RSA total score is used as a global index of resilience: higher score reflects higher resilience. In this study, we also used the scores of each subscale, to identify which factors are more closely associated with psychosocial functioning and psychiatric symptoms. The internal consistency of the subscales was satisfactory, ranging from 0.67 to 0.90 ; also, the test-retest correlations were all good for the subscales of RSA, ranging from 0.69 to 0.84 $(p<0.01)$. We used an Italian version of the scale comprising a five-point semantic differential, which is easier to understand for the poorly educated population or subjects with cognitive impairment, like some of those affected by schizophrenia. ${ }^{46}$

\section{Brief Psychiatric Rating Scale-Anchored version (BPRS-A)}

BPRS-A is one of the best known tools for the assessment of general psychopathology used in restricted settings. ${ }^{47}$ BPRSA assesses expected symptoms and problems in psychiatric patients. It is a hetero-administered 24-item scale rated in interview format using Likert scale ratings from 1 ("absent") to 7 ("very severe").

\section{Scale for the Assessment of Negative Symptoms (SANS)}

SANS is a 25 -item scale used by clinicians to measure negative symptoms in patients with schizophrenia. ${ }^{48}$ Assessments are conducted on a six-point scale $(0=$ not at all to $5=$ severe $)$; the items are divided into five subscales: "affective flattening or blunting," "alogia," "avolition-apathy," "anhedoniaasociality," and "attention." Cronbach's alpha and test-retest reliability were 0.83 and 0.79 , respectively.

\section{Scale for the Assessment of Positive Symptoms (SAPS)}

SAPS is a 34 -item six-point scale ( $0=$ not at all to $5=$ severe $)$ designed to assess positive symptoms in psychotic patients. ${ }^{49}$ This instrument is designed to be complementary to SANS; positive symptoms can be divided into four different categories: "hallucinations," "delusions," "bizarre behavior," and "positive formal thought disorders." Alpha reliability was 0.75 , and test-retest reliability was 0.73 .

\section{Life Skills Profile (LSP)}

LSP is an assessment scale administered by psychiatrists, nonexperts (such as family members), and paramedical staff that explores many aspects of functioning. ${ }^{50}$ It consists of 39 multiple choice items with four alternatives of response, and a corresponding score of 1 (negative end) to 4 (positive end) It is possible to calculate a total score (which can range from a minimum of 39 to a maximum of 156), and a score for each of the five subscales, which refer to distinct social benefits in everyday life: "self-care" (10 items), "non-turbulence" (12 items), "social contact" (six items), "communicative" 
(six items), and "responsibility" (five items). Higher scores correspond to better functioning. For this study, we used the Italian validated version of the scale. An alpha coefficient and a test-retest reliability of 0.88 and 0.79 have been reported, respectively.

An Italian validated version for each scale was used. ${ }^{51,52}$

\section{Statistical analysis}

Continuous variables of the study were summarized using mean and SD, while categorical variables were expressed as relative frequencies.

Independent $t$-test was used to evaluate any statistically significant difference between patients with schizophrenia and those affected by schizoaffective disorder.

Partial correlations were used to assess the relationship between resilience and its dimensions, based on RSA total scores and subscores, with psychosocial functioning (LSP total score), psychopathology (BPRS total score), positive psychotic symptoms (SAPS total score), and negative psychotic symptoms (SANS total score), being aware of the effect of any possible variable not directly considered in the analysis, removing thus the common variance among variables. Two multiple linear regression models were used to examine the association between resilience and psychopathology and between resilience and psychosocial functioning; we used in both cases a hierarchical method to understand the effect of the single predictor and to reduce the common variance among variables and exclude less important variables.

In the first analysis (model 1), BPRS-A total score was set as a dependent variable; the predictors subsequently added were "RSA perception of self," "RSA perception of the future," and "RSA structured style," followed by "RSA social resources" and "RSA social competence." Predictors were entered in this order, based on the correlation results. We removed the subscale "RSA family cohesion" from this analysis since there was no significant correlation with general psychopathology. In the second analysis (model 2), LSP total score was set as the dependent variable; the predictors included in the model were "RSA family cohesion" and "RSA social resources," entered in this order, as they were the only subscales showing significant correlation with psychosocial functioning.

A series of multiple linear regression analysis with the calculation of direct, mediated, and total effect were finally used to estimate the interplay between resilience factors and psychopathology on psychosocial functioning. In the present study, each resilient factor was considered as a possible mediator between the symptoms and functioning: consequently, we first valued BPRS-A's effect on each of the resilient factors; then, we assessed BPRS-A's and RSA factor's effect on global functioning; finally, we calculated the direct, mediated, and total effect of resilient factors and psychopathology on psychosocial functioning.

\section{Results}

\section{Demographic and clinical data}

Among the 200 patients evaluated, 122 patients met the inclusion criteria. The average age was 48.8 years (SD 11.80 ), with $67 \%$ males and $33 \%$ females. Among these, $77 \%$ of patients $(\mathrm{N}=94)$ had a diagnosis of schizophrenia and $23 \%(\mathrm{~N}=28)$ a diagnosis of schizoaffective disorder. At recruitment, the average duration of disease history of the patients was 23.1 years (SD 10.6), with the first psychotic episode occurring at the average age of 25.5 years (SD 7.1). Descriptive statistics of demographic and clinical variables are provided in Table 1.

At recruitment, the average RSA total score was 109.80 (SD 20.9), the average BPRS-A score was 48.3 (SD 12), the average SANS total score was 62.3 (SD 26.3), while the average SAPS total score was 26.4 (SD 19); finally, the average LSP total score was 120.3 (SD 12.7), as shown in Table 2 .

Table I Characteristics of the sample $(\mathrm{N}=122)$

\begin{tabular}{ll}
\hline Gender (male/female) & $82 / 40$ \\
Age (years, mean SD) & $48.8 \pm 11.8$ \\
Education (years, mean SD) & $10.1 \pm 2.8$ \\
Age at first psychotic episode (years, mean SD) & $25.5 \pm 7.1$ \\
History of disease (years, mean SD) & $23.1 \pm 10.6$ \\
Diagnosis (schizophrenia/schizoaffective disorder) & $94 / 28$ \\
\hline
\end{tabular}

Table 2 Data on resilience, psychopathology, and psychosocial functioning

\begin{tabular}{lll}
\hline & Mean & Min/max \\
\hline RSA total score & 109.8 & $49 / 153$ \\
RSA perception of self & 19.64 .9 & $8 / 30$ \\
RSA perception of the future & 11.2 & $4 / 20$ \\
RSA structured style & 13.1 & $7 / 20$ \\
RSA social competence & 20.5 & $9 / 30$ \\
RSA family cohesion & 26.3 & $11 / 35$ \\
RSA social resources & 19.1 & $6 / 30$ \\
BPRS-A total score & 48.3 & $28 / 89$ \\
SANS total score & 62.3 & $5 / 141$ \\
SAPS total score & 26.4 & $0 / 69$ \\
LSP total score & 120.3 & $82 / 143$ \\
\hline
\end{tabular}

Abbreviations: RSA, Resilience Scale for Adults; BPRS-A, Brief Psychiatric Rating Scale-Anchored version; SANS, Scale for the Assessment of Negative Symptoms; SAPS, Scale for the Assessment of Positive Symptoms; LSP, Life Skills Profile; min, minimum; max, maximum. 


\section{Primary results}

Independent $t$-test between the two groups (schizophrenia and schizoaffective disorder) and partial correlations among resilience, psychotic symptoms, and psychosocial functioning

First of all, we investigated differences between the two different psychotic disorders under consideration: schizophrenia and schizoaffective disorder. As shown in Table 3, there were no statistically significant differences in any of the scales and subscales between the two groups compared; therefore, we did not perform any group-specific analysis.

Partial correlations are presented in Table 4. Common variance among BPRS-A, SANS, SAPS, and LSP was eliminated in order to better investigate the relationship among variables. A statistically significant negative correlation

Table 3 Independent $t$-test between schizophrenia and schizoaffective disorder

\begin{tabular}{|c|c|c|c|c|c|c|c|}
\hline & \multicolumn{2}{|c|}{$\begin{array}{l}\text { Group A } \\
\text { (schizophrenia) } \\
(\mathrm{N}=94)\end{array}$} & \multicolumn{2}{|c|}{$\begin{array}{l}\text { Group B (schizoaffective } \\
\text { disorder) } \\
(\mathrm{N}=28) \\
\end{array}$} & \multicolumn{3}{|l|}{$p$} \\
\hline & Mean & SD & Mean & SD & $t$ & df & Sig (2-tail) \\
\hline RSA total score & 110.49 & 18.925 & 107.57 & 26.796 & 0.538 & 35.392 & 0.594 \\
\hline RSA perception of self & 20.23 & 4.948 & 17.29 & 4.081 & 3.188 & 52.876 & 0.062 \\
\hline RSA perception of the future & 11.43 & 3.772 & 10.36 & 4.365 & 1.171 & 39.774 & 0.248 \\
\hline RSA structured style & 13.06 & 3.072 & 13.36 & 3.165 & -0.433 & 43.292 & 0.667 \\
\hline RSA social competence & 20.96 & 4.925 & 19.00 & 6.896 & 1.399 & 35.589 & 0.170 \\
\hline RSA social support & 26.21 & 5.491 & 26.71 & 7.358 & -0.334 & 36.409 & 0.740 \\
\hline RSA family cohesion & 18.60 & 6.137 & 20.86 & 7.179 & -1.511 & 39.492 & 0.139 \\
\hline BPRS-A total score & 51.93 & 17.965 & 47.17 & 10.632 & -1.334 & 32.824 & 0.191 \\
\hline SANS total score & 52.57 & 14.477 & 65.21 & 28.337 & 3.158 & 89.828 & 0.062 \\
\hline SAPS total score & 34.00 & 19.634 & 24.17 & $\mid 8.331$ & -2.360 & 42.019 & 0.073 \\
\hline LSP total score & 118.07 & 16.328 & 121.00 & 11.435 & 0.887 & 35.247 & 0.381 \\
\hline
\end{tabular}

Abbreviations: RSA, Resilience Scale for Adults; BPRS-A, Brief Psychiatric Rating Scale-Anchored version; SANS, Scale for the Assessment of Negative Symptoms; SAPS, Scale for the Assessment of Positive Symptoms; LSP, Life Skills Profile; df, degrees of freedom; Sig, statistical significance.

Table 4 Partial correlations between resilience, symptomatology, and psychosocial functioning

\begin{tabular}{|c|c|c|c|c|c|}
\hline & & $\begin{array}{l}\text { BPRS-A total score } \\
\text { (contr var: } \\
\text { SANS-SAPS-LSP) }\end{array}$ & $\begin{array}{l}\text { SANS total score } \\
\text { (contr var: } \\
\text { BPRS-A-SAPS-LSP) }\end{array}$ & $\begin{array}{l}\text { SAPS total score } \\
\text { (contr var: } \\
\text { BPRS-A-SANS-LSP) }\end{array}$ & $\begin{array}{l}\text { LSP total score } \\
\text { (contr var: } \\
\text { BPRS-A-SANS-SAPS) }\end{array}$ \\
\hline \multirow[t]{2}{*}{ RSA total score } & Correlation & $-0.387^{* * *}$ & $0.220^{*}$ & 0.170 & 0.149 \\
\hline & Sig (2 tails) & $<0.0001$ & 0.016 & 0.065 & 0.105 \\
\hline RSA perception & Correlation & $-0.448 * * *$ & 0.168 & 0.057 & -0.111 \\
\hline of self & Sig (2 tails) & $<0.0001$ & 0.068 & 0.539 & 0.228 \\
\hline RSA perception & Correlation & $-0.408 * * *$ & 0.050 & 0.062 & -0.145 \\
\hline of the future & Sig (2 tails) & $<0.0001$ & 0.588 & 0.505 & 0.115 \\
\hline RSA structured & Correlation & $-0.292 * * *$ & 0.107 & 0.084 & 0.054 \\
\hline style & Sig (2 tails) & 0.001 & 0.247 & 0.366 & 0.558 \\
\hline RSA social & Correlation & $-0.202 *$ & 0.114 & 0.058 & 0.114 \\
\hline competence & Sig (2 tails) & 0.027 & 0.215 & 0.528 & 0.215 \\
\hline RSA social & Correlation & $-0.219 *$ & 0.151 & 0.147 & $0.198 *$ \\
\hline resources & Sig (2 tails) & 0.017 & 0.102 & 0.111 & 0.031 \\
\hline RSA family & Correlation & -0.102 & $0.224^{*}$ & $0.204^{*}$ & $0.29 I^{* * *}$ \\
\hline \multirow[t]{2}{*}{ cohesion } & Sig (2 tails) & 0.271 & 0.014 & 0.026 & 0.001 \\
\hline & & $\begin{array}{l}\text { BPRS-A total score } \\
\text { (contr var: } \\
\text { SANS-SAPS-RSA) }\end{array}$ & $\begin{array}{l}\text { SANS total score } \\
\text { (contr var: } \\
\text { BPRS-A-SAPS-RSA) }\end{array}$ & $\begin{array}{l}\text { SAPS total score } \\
\text { (contr var: } \\
\text { BPRS-A-SANS-RSA) }\end{array}$ & \\
\hline \multirow[t]{2}{*}{ LSP total score } & Correlation & $-0.386 * * *$ & $-0.32 I^{* * *}$ & -0.163 & \\
\hline & Sig (2 tails) & 0.000 & 0.000 & 0.076 & \\
\hline
\end{tabular}

Note: $* * * p \leq 0.001$; and $* p \leq 0.05$.

Abbreviations: RSA, Resilience Scale for Adults; BPRS-A, Brief Psychiatric Rating Scale-Anchored version; SANS, Scale for the Assessment of Negative Symptoms; SAPS, Scale for the Assessment of Positive Symptoms; LSP, Life Skills Profile; contr var, control variables; Sig, statistical significance. 
$(p<0.001)$ among BPRS-A total score (general psychiatric symptomatology severity), RSA total score, "RSA perception of self," "RSA perception of the future," and "RSA structured style" emerged (correlation coefficients $=-0.448$ to $-0.292, p<0.001)$. However, a weak negative correlation among BPRS-A total score, "RSA social competence," and "RSA social resources" was observed (correlation coefficients $=-0.219$ to $-0.202, p<0.017-0.027)$. With regard to the SANS total score, only a weak positive correlation with RSA total score and "RSA family cohesion" emerged (correlation coefficients $0.220-0.224, p<0.014-0.016$ ); similarly, SAPS total score was only positively correlated with resilience's subscale "family cohesion" (correlation coefficients $=0.204, p<0.026$ ).

Psychosocial functioning instead was significantly and positively correlated with resilience only by the subscales "RSA family cohesion" (correlation coefficients $=0.291$, $p<0.001$ ) and "RSA social resources" (correlation coefficients $=0.198, p<0.031$ ).

\section{Secondary results}

\section{Hierarchical linear regression}

Results from multiple regression analyses are displayed in Table 5. In model 1, BPRS-A total score was set as a dependent variable; the predictors subsequently added were RSA perception of self, RSA perception of the future, RSA structured style, RSA social resources, and RSA social competence. Predictors were entered in this order, based on the correlation results: we removed the subscale "RSA family cohesion" from these analysis since there was no significant correlation with general psychopathology. Three different possibilities were obtained: model $1 \mathrm{C}$, comprising "RSA perception of self," "RSA structured style," and "RSA perception of the future," explained $31.5 \%$ of the general psychopathology variance in the sample being examined $\left(\mathrm{R}^{2}=0.315, \mathrm{~F}(118)=18.1, p<0.001\right)$; "RSA social resources" and "RSA social competence" were not been included in the final model because they did not have a statistically significant beta value. Particularly, "RSA perception of self" was negatively associated with BPRS-A ( $b=-285$, $\mathrm{SEM}=0.249, p<0.05)$, suggesting that in psychotic patients higher "RSA self-perception" scores corresponded to lower BPRS-A. Also, "RSA structured style" ( $b=-235$, $\mathrm{SEM}=0.302, p<0.05)$ and "RSA perception of the future" $(b=-205$, SEM $=0.336, p<0.05$ ) were negatively associated with BPRS-A total score, showing that the ability to plan and organize life events and good expectations for the future are important protective factors against development of severe psychiatric symptoms.

In model 2, LSP total score was set as the dependent variable; the predictors subsequently added were the two RSA subscales statistically correlated with psychosocial functioning, which were "RSA family cohesion" and "RSA social resources." The final model revealed that only "RSA social resources" had a statistically significant beta value $(b=0.334, \mathrm{SEM}=0.184, p<0.001)$ and explained $11.2 \%$ of the psychosocial functioning variance in the clinical sample $\left(\mathrm{R}^{2}=0.112, \mathrm{~F}(120)=15.0, p<0.001\right)$, while the other subscales did not show a statistically significant association with LSP. Results showed that only social resources are related to better psychosocial functioning.

Multiple linear regression and calculation of direct, mediated, and total effect of resilience factors and psychopathology on psychosocial functioning

Results from the multiple regression analyses and calculation of direct, mediated, and total effect between resilience factors and psychopathology on psychosocial functioning are shown in Table 6 . In our sample, only a very weak partial mediation in observed; no resilient factor was able to significantly influence the direct effect of psychopathology on psychosocial functioning.

Table 5 Hierarchical linear regression with psychotic symptomatology and psychosocial functioning

\begin{tabular}{|c|c|c|c|c|c|c|c|}
\hline & Predictors & Dependent variable & $\mathbf{R}$ & $\mathbf{R}^{2}$ & $\mathbf{F}$ & Beta & SEM \\
\hline Model IA & RSA perception of self & BPRS-A & 0.482 & 0.232 & $36.2^{* * *}$ & $-0.482^{* * *}$ & 0.208 \\
\hline \multirow[t]{2}{*}{ Model IB } & RSA perception of self & & & & & $-0.397 * * *$ & $0.24 \varepsilon$ \\
\hline & RSA structured style & BPRS-A & 0.536 & 0.287 & $23.9 * * *$ & $-0.250 * * *$ & 0.311 \\
\hline \multirow[t]{3}{*}{ Model IC } & RSA perception of self & & & & & $-0.285^{* * *}$ & 0.249 \\
\hline & RSA structured style & BPRS-A & $0.56 \mathrm{I}$ & 0.315 & $18.1^{* * * *}$ & $-0.235^{* *}$ & 0.302 \\
\hline & RSA perception of the future & & & & & $-0.205^{* * * * *}$ & 0.336 \\
\hline Model 2 & RSA social resources & LSP & 0.334 & 0.112 & $15.0^{* * * *}$ & $0.334 * * *$ & 0.184 \\
\hline
\end{tabular}

Note: $* * * p \leq 0.001$; and $* * p \leq 0.01$.

Abbreviations: RSA, Resilience Scale for Adults; BPRS-A, Brief Psychiatric Rating Scale-Anchored version; LSP, Life Skills Profile; SEM, standard error of the mean. 
Table 6 Multiple linear regression and calculation of direct, mediated, and total effect of resilience factors and psychopathology on psychosocial functioning

\begin{tabular}{|c|c|c|c|c|c|c|c|c|c|}
\hline \multirow[t]{2}{*}{ Predictor } & \multirow[t]{2}{*}{ Mediator } & \multirow[t]{2}{*}{$\begin{array}{l}\text { Dependent } \\
\text { variable }\end{array}$} & \multicolumn{2}{|c|}{$\begin{array}{l}\text { Predictor's effect on } \\
\text { mediator }\end{array}$} & \multicolumn{2}{|c|}{$\begin{array}{l}\text { Predictor's and mediator's } \\
\text { effect on dependent variable }\end{array}$} & \multirow[t]{2}{*}{$\begin{array}{l}\text { Direct } \\
\text { effect }\end{array}$} & \multirow[t]{2}{*}{$\begin{array}{l}\text { Mediated } \\
\text { effect }\end{array}$} & \multirow[t]{2}{*}{$\begin{array}{l}\text { Total } \\
\text { effect }\end{array}$} \\
\hline & & & B & Beta & B & Beta & & & \\
\hline BPRS-A & - & LSP & - & - & -0.656 & $-0.656 * * *$ & - & - & -0.656 \\
\hline BPRS-A & $\begin{array}{l}\text { RSA perception } \\
\text { of self }\end{array}$ & LSP & -0.185 & $-0.482 * * *$ & $\begin{array}{l}-0.722 \\
-0.370\end{array}$ & $\begin{array}{l}-0.725^{* * *} \\
-0.143\end{array}$ & -0.722 & 0.068 & -0.656 \\
\hline BPRS-A & $\begin{array}{l}\text { RSA perception } \\
\text { of future }\end{array}$ & LSP & -0.131 & $-0.426 * * *$ & $\begin{array}{l}-0.713 \\
-0.455\end{array}$ & $\begin{array}{l}-0.716^{* * *} \\
-0.141\end{array}$ & -0.713 & 0.059 & -0.654 \\
\hline BPRS-A & $\begin{array}{l}\text { RSA structured } \\
\text { style }\end{array}$ & LSP & -0.093 & $-0.384 * * *$ & $\begin{array}{l}-0.647 \\
0.072\end{array}$ & $\begin{array}{l}-0.650 * * * \\
0.018\end{array}$ & -0.647 & -0.006 & -0.653 \\
\hline BPRS-A & $\begin{array}{l}\text { RSA social } \\
\text { competence }\end{array}$ & LSP & -0.138 & $-0.32 I^{* * * *}$ & $\begin{array}{l}-0.632 \\
0.154\end{array}$ & $\begin{array}{l}-0.635^{* * *} \\
0.066\end{array}$ & -0.632 & -0.021 & -0.653 \\
\hline BPRS-A & $\begin{array}{l}\text { RSA social } \\
\text { resources }\end{array}$ & LSP & -0.158 & $-0.340 * * *$ & $\begin{array}{l}-0.611 \\
0.267\end{array}$ & $\begin{array}{l}-0.614^{* * *} \\
0.125\end{array}$ & -0.611 & -0.042 & -0.653 \\
\hline BPRS-A & $\begin{array}{l}\text { RSA family } \\
\text { cohesion }\end{array}$ & LSP & -0.101 & $-0.20 I^{*}$ & $\begin{array}{l}-0.618 \\
0.347\end{array}$ & $\begin{array}{l}-0.621^{* * *} \\
0.176^{*}\end{array}$ & -0.618 & -0.035 & -0.653 \\
\hline
\end{tabular}

Note: $* * * p \leq 0.001$; and $* p \leq 0.05$.

Abbreviations: BPRS-A, Brief Psychiatric Rating Scale-Anchored version; LSP, Life Skills Profile; RSA, Resilience Scale for Adults.

\section{Discussion}

The originality of this study consists in considering different intrapersonal and interpersonal factors of resilience in psychotic people, in order to identify any associations among these factors and psychosocial functioning or symptoms; in contrast, scientific literature evaluates resilience as a unitary construct, not valorizing its dimensions. ${ }^{1-3,42}$

Mastering resilience and its factors could allow the creation of customized therapeutic plans, built from the individual resources of each patient and able to improve the social functioning or reduce the discomfort arising from the symptoms.

According to the literature, ${ }^{1-3,42}$ in this study no strong correlation among resilience and positive and negative psychotic symptoms was observed. A weak positive correlation between resilient dimension inherent in family support and positive and negative symptoms severity emerged, as well as a weak positive correlation between resilience and negative psychotic symptoms. These unexpected results could suggest how an important addiction to the family could be counterproductive for psychotic people: excessive stimulation could be connected to the persistence of positive symptoms, while on the contrary an overprotective environment could promote negative symptoms; these hypotheses require and deserve to be verified with other studies.

However, statistically strong associations between resilience and general psychiatric symptoms emerged. Specifically, no association between interpersonal resilient factors, such as family or social resources, and symptoms severity was found: social support did not have a predictive role in mental illness severity. On the contrary, according to some authors, we found that intrapersonal resilient factors, such as a good perception on one's own capabilities and a structured style, allow psychotic patients to overcome symptoms distress: ${ }^{11,12,19}$ the better the self-perception, expectations for the future, and the ability to plan and organize the routine, the less the perception of psychological discomfort.

Interventions aimed at the recognition and use of personal resilient resources in specific recovery strategies, such as psychological, psychosocial, and rehabilitative programs, could be effective to reduce symptomatology, especially in patients clinically stable and not in the acute phase. ${ }^{39-41,50,51,53,54}$

As far as the relationship between resilience and psychosocial functioning is concerned in psychotic patients, some studies have shown direct correlation, while other research have shown how resilience can act as a mediator between illness-related variables and real-life functioning. ${ }^{1,2}$ In the present study, only the interpersonal resilient factor associated with social resources is directly related to psychosocial functioning; furthermore, in our sample, resilient factors must be considered as intervening variables between symptoms and functioning and not as mediators between psychopathology and global functioning. According to the literature, ${ }^{1,13,18,39-41}$ interpersonal relationships and external support could help people to achieve better functional recovery, even in patients with schizophrenia. Resilience factors 
could therefore be considered as important elements in social skill training programs and recovery strategies to improve real-life functioning. ${ }^{39-41,55}$

In conclusion, data show that intrapersonal resilient factors can predict psychiatric symptoms severity and explain $\sim 31 \%$ of the BPRS-A variance; only the interpersonal resilient factor associated with social support can predict psychosocial functioning, explaining the $11 \%$ of LSP variance. The selected sample was stable, and the mean psychopathological scores were relatively low.

The specific contribution that resilience factors may have in predicting the severity of symptoms and the extent of psychosocial functioning emphasizes the importance to personalize treatments for patients affected by schizophrenia, to promote personal resources and translate them into better outcomes.

Despite the strengths of this study, the particularity of the sample, and the choice to evaluate different factors of resilience to identify specific predictors, there are some limitations such as the small sample size and the design of the study. A future proposal is the evaluation of a larger sample and follow-up in order to allow the identification of causal links.

\section{Disclosure}

The authors report no conflicts of interest in this work.

\section{References}

1. Kim KR, Song YY, Park JY, et al. The relationship between psychosocial functioning and resilience and negative symptoms in individuals at ultra-high risk for psychosis. Aust N Z J Psychiatry. 2013;47(8): $762-771$.

2. Galderisi S, Rossi A, Rocca P, et al; Italian Network For Research on Psychoses. The influence of illness-related variables, personal resources and context-related factors on real-life functioning of people with schizophrenia. World Psychiatry. 2014;13(3):275-287.

3. Rossi A, Galderisi S, Rocca P, et al; Italian Network for Research on Psychoses. The relationships of personal resources with symptom severity and psychosocial functioning in persons with schizophrenia: results from the Italian Network for Research on Psychoses study. Eur Arch Psychiatry Clin Neurosci. 2017;267(4):285-294.

4. Luthar S. Resilience and Vulnerability: Adaptation in the Context of Childhood Adversities. New York: Cambridge University Press; 2003.

5. Rutter M. Implications of resilience concepts for scientific understanding. Ann NY Acad Sci. 2006;1094:1-12.

6. Kim-Cohen J. Resilience and developmental psychopathology. Child Adolesc Psychiatr Clin N Am. 2007;16(2):271-283.

7. Callegari C, Bertù L, Caselli I, et al. Resilience in older adults: influence of the admission in nursing home and psychopatology. Neuropsychiatry. 2016;6(4):117-123.

8. Callegari C, Bertù L, Lucano M, Ielmini M, Braggio E, Vender S. Reliability and validity of the Italian version of the 14-item resilience scale. Psychol Res Behav Manag. 2016;3(9):277-284.

9. Laudadio A, Fiz Perez F, Mazzocchetti L. Valutare la resilienza. Teorie, modelli e strumenti. Ricerche edizioni, vol 10. Roma: Carrocci; 2011. Italian.
10. Werner E. High-risk children in young adulthood: a longitudinal study from birth to 32 years. Am J Orthopsychiatry. 1989;59(1):72-81.

11. Rutter M. Psychosocial resilience and protective mechanisms. Am J Orthopsychiatry. 1987;57(3):316-331.

12. Garmezy N. Children in poverty: resilience despite risk. Psychiatry. 1993;56(1):127-136.

13. Werner E. Risk, resilience and recovery: perspectives from the Kauai longitudinal study. Dev Psychopathol. 1993;5(4):503-515.

14. Cederblad M, Dahlin L, Hagnell O, Hansson K. Salutogenic childhood factors reported by middle-aged individuals. Follow-up of the children from the Lundby study grown up in families experiencing three or more childhood psychiatric risk factors. Eur Arch Psychiatry Clin Neurosci. 1994;244(1):1-11.

15. Mandeco B, Perry J. An organizational framework for conceptualizing resilience in children. $J$ Child Adolesc Psychiatr Nurs. 2000;13(3):99-111.

16. Werner E, Smith R. Journeys from Childhood to Midlife: Risk, Resilience and Recovery. Ithaca, NY: Cornell University Press; 2001.

17. Salmon P, Dowrick C, Ring A, Humphris G. Voiced but unheard agendas: qualitative analysis of the psychosocial cues that patients with unexplained symptoms present to general practitioners. Br J Gen Pract. 2004;54(3):171-176.

18. Dowrick C, Kokanovic R, Hegarty K, Griffiths F, Gunn J. Resilience and depression: perspectives from primary care. Health (London). 2008;12(4):439-452.

19. Werner E, Smith R. Overcoming the Odds. High Risk Children from Birth to Adulthood. Ithaca, NY: Cornell University Press; 1992.

20. Milioni M, Alessandri G, Eisenberg N, et al. Reciprocal relations between emotional self-efficacy beliefs and ego-resiliency across time. J Pers. 2015;83(5):552-563.

21. Afifi TO, Macmillan HL. Resilience following child maltreatment: a review of protective factors. Can J Psychiatry. 2011;56(5):266-272.

22. Luthar S, Doernberger C, Zigler, E. Resilience is not a unidimensional construct: insights from a prospective study of inner-city adolescents. Dev Psychopathol. 1993;5(4):703-717.

23. Luthar S, Cicchetti D, Becker B. The construct of resilience: a critical evaluation and guidelines for future work. Child Dev. 2000;71(3): 543-562.

24. McGlashan T, Levy S, Carpenter W. Integration and sealing over. Clinically distinct recovery styles from schizophrenia. Arch Gen Psychiatry. 1975;32(10):1269-1272.

25. Rudnick A, Martins J. Coping and schizophrenia: a re-analysis. Arch Psychiatr Nurs. 2009;23(1):11-15.

26. Poloni N, Callegari C, Buzzi A, et al. Validazione della versione italiana delle scale ISOS e RSQ per lo studio del recovery style nei disturbi psicotici [The Italian version of ISOS and RSQ, two suitable scales for investigating recovery style from psychosis]. Epidemiol Psichiatr Soc. 2010;19(4):352-359. Italian.

27. Poloni N, Diurni M, Buzzi A, et al. [Recovery style, symptoms and psychosocial functioning in psychotic patients: a preliminary study]. Riv Psichiatr. 2013;48(5):386-392. Italian.

28. Fleischhacker W, Arang C, Arteel P, et al. Schizophrenia - time to commit to policy change. Schizophr Bull. 2014;40(Suppl 3):165-194.

29. Eack S, Newhill C. Psychiatric symptoms and quality of life in schizophrenia: a meta-analysis. Schizophr Bull. 2007;33(5):1225-1237.

30. Leifker F, Bowie C, Harvey P. Determinants of everyday outcomes in schizophrenia: the influences of cognitive impairment, functional capacity, and symptoms. Schizophr Res. 2009;115(1):133-136.

31. Magliano L, Fadden G, Economou M, et al. Family burden and coping strategies in schizophrenia: 1-year follow-up data from the BIOMED I study. Soc Psychiatry Psychiatr Epidemiol. 2000;35(3): 109-115.

32. Magliano L, Fiorillo A, De Rosa C, Malangone C, Maj M. Family burden in long-term disease: comparative study in schizophrenia vs. physical disorders. Soc Sci Med. 2005;61(2):313-322.

33. Poloni N, Armani S, Ielmini M, et al. Characteristics of the caregiver in mental health: stress and strain. Minerva Psichiatr. 2017;58(3):118-124. 
34. Schaub D, Brune M, Jaspen E, Pajonk F, Bierhoff H, Juckel G. The illness and everyday living: close interplay of psychopathological syndromes and psychosocial functioning in chronic schizophrenia. Eur Arch Psychiatr Clin Neurosci. 2011;261(2):85-93.

35. Harvey P, Strassnig M. Predicting the severity of everyday functional disability in people with schizophrenia: cognitive deficits, functional capacity, symptoms and health status. World Psychiatry. 2012;11(2):73-79.

36. San L, Ciudad A, Alvarez E, Bobes J, Gilaberte I. Symptomatic remission and social/vocational functioning in outpatients with schizophrenia: prevalence and associations in a cross-sectional study. Eur Psychiatry. 2007;22(8):490-498

37. Lambert M, Karow A, Leucht S, Schimmelmann B, Naber D. Remission in schizophrenia: validity, frequency, predictors, and patients' perspective 5 years later. Dialogues Clin Neurosci. 2010;12(3):393-407.

38. Oorschot M, Lataster T, Thewissen V, et al. Symptomatic remission in psychosis and real-life functioning. Br J Psychiatry. 2012;201(3):215-220.

39. Harrow M, Jobe TH. Factors involved in outcome and recovery in schizophrenia patients not on antipsychotic medication: a 15-year multifollow-up study. J Nerv Ment Dis. 2007;195(5):406-414.

40. Pilling S, Bebbington P, Kuipers E, et al. Psychological treatments in schizophrenia: II. Meta-analyses of randomized controlled trials of social skills training and cognitive remediation. Psychol Med. 2002;32(5):783-791.

41. Semisa D, Casacchia M, Di Munzio W, et al; Gruppo SIEP-DIRECT'S. Promuovere il recupero dei pazienti con schizofrenia: discrepanze fra pratiche di routine ed evidenze. Il progetto SIEP-DIRECT'S [Promoting recovery of schizophrenic patients: discrepancy between routine practice and evidence. The SIEP-DIRECT'S Project]. Epidemiol Psichiatr Soc. 2008;17(4):331-349. Italian.

42. Rossi A, Galderisi S, Rocca P, et al; Italian Network for Research on Psychoses. Personal resources and depression in schizophrenia: the role of self-esteem, resilience and internalized stigma. Psychiatry Res. 2017;256:359-364.

43. Friborg O, Hjemdal O, Rosenvinge JH, Martinussen M. A new rating scale for adult resilience: what are the central protective resources behind healthy adjustment? Int J Methods Psychiatr Res. 2003;12(2):65-76.
44. Friborg O, Barlaug D, Martinussen M, Rosenvinge JH, Hjemdal O. Resilience in relation to personality and intelligence. Int $J$ Methods Psychiatr Res. 2005;14(1):29-42.

45. Friborg O, Hjemdal O, Rosenvinge JH, Martinussen M, Aslaksen PM, Flaten MA. Resilience as a moderator of pain and stress. J Psychosom Res. 2006;61(2):213-219.

46. Bonfiglio NS, Renati R, Hjemdal O, Friborg O. The resilience scale for adults in Italy: a validation study comparing clinical substance abusers with a nonclinical sample. Psychol Addict Behav. 2016;30(4):509-515.

47. Overall JE, Gorham DR. The brief psychiatric rating scale (BPRS) Psychol Rep. 1962;10:799-812.

48. Andreasen NC. Scale for the Assessment of Negative Symptoms (SANS). Iowa: Department of Psychiatry, College of Medicine, University of Iowa; 1984.

49. Andreasen NC. Scale for the Assessment of Positive Symptoms (SAPS). Iowa: Department of Psychiatry, College of Medicine, University of Iowa; 1984.

50. Rosen A, Hadzi-Pavlov D, Parker G. The Life Skills Profile: a measure assessing function and disability in schizophrenia. Schizophr Bull. 1989;15(2):325-337.

51. Roncone R, Ventura J, Impallomeni M, et al. Reliability of an Italian standardized and expanded Brief Psychiatric Rating Scale (BPRS 4.0) in raters with high vs. low clinical experience. Acta Psychiatr Scand. 1999;100(3):229-236

52. Zizolfi S. La versione italiana del Life Skills Profile (LSP), uno strumento per la valutazione del funzionamento e delle disabilità dei pazienti schizofrenici. Epidemiol Psychiatr Sci. 1997;6(3):196-204. Italian.

53. Hogarty GE. Personal Therapy for Schizophrenia and Related Disorders: A Guide to Individualized Treatment. New York: Guilford Press; 2002.

54. Rummel-Kluge C, Kissling W. Psychoeducation in schizophrenia: new developments and approaches in the field. Curr Opin Psychiatry. 2008;21(2):168-172.

55. Kurtz MM, Mueser KT. A meta-analysis of controlled research on social skills training for schizophrenia. J Consult Clin Psychol. 2008;76(3):491-504.
Psychology Research and Behavior Management

\section{Publish your work in this journal}

Psychology Research and Behavior Management is an international, peerreviewed, open access journal focusing on the science of psychology and its application in behavior management to develop improved outcomes in the clinical, educational, sports and business arenas. Specific topics covered in the journal include: Neuroscience, memory and decision making; Behavior

\section{Dovepress}

modification and management; Clinical applications; Business and sports performance management; Social and developmental studies; Animal studies. The manuscript management system is completely online and includes a very quick and fair peer-review system, which is all easy to use. Visit http://www. dovepress.com/testimonials.php to read real quotes from published authors. 